\title{
PENGARUH KEADILAN ORGANISASIONAL, KESEMPATAN PROMOSI, LINGKUNGAN KERJA, DAN JOB EMBEDDEDNESS TERHADAP TURNOVER INTENTIONS KARYAWAN MILLENIAL
}

\author{
Riska Fii Ahsani ${ }^{1}$, Dorothea Ririn Indriastuti ${ }^{2}{ }^{2}$ Sunarso ${ }^{3}$, Hana Mega ${ }^{4}$ \\ Program Studi Manajemen Fakultas Ekonomi Universitas Slamet Riyadi Surakarta ${ }^{1,2,3}$ \\ email : riskafii@gmail.com, sunarso66@gmail.com, indriastuti_ririn@yahoo.co.id
}

\begin{abstract}
Info Artikel
Masuk: 12 November 2020

Revisi: 25 November 2020

Diterima: 8 Desember 2020

Terbit: 12 Januari 2021

\section{Kata kunci:}

Keadilan Organisasional, Kesempatan Promosi, Lingkungan Kerja, Job Embeddedness, Turnover Intentions.
\end{abstract}

\section{Keywords:}

Organizational Justice, Promotion Opportunities, Work environment, Job Embeddedness, Turnover Intentions.

P-ISSN: 2550-0171

E-ISSN: 2580-5819

DOI : 103661

\begin{abstract}
Fenomena job hopping atau berpindah-pindah tempat kerja muncul pada generasi milenial. Turnover intention merupakan dampak terburuk yang disebabkan oleh ketidakmampuan suatu organisasi untuk mengelola perilaku individu, sehingga individu merasa memiliki intensi pindah kerja yang tinggi. Tingginya tingkat turnover intention pada kayawan milenial akan menimbulkan dampak negatif bagi perusahaan yang dapat menciptakan ketidakstabilan dan menunjukkan bahwa perusahaan tersebut tidak efektif, oleh sebab itu suatu perusahaan harus mengetahui faktor-faktor yang dapat menyebabkan turnover intention. Tujuan penelitian ini adalah untuk menguji pengaruh Keadilan Organisasional, Kesempatan Promosi, Lingkungan Kerja dan dan Job Embeddedness terhadap Turnover Intentions. Penelitian ini dilakukan pada sejumlah perusahaan dan UMKM yang bergerak pada industri jasa seperti restoran, hotel, rumah sakit, dan salon. Pengambilan sampel menggunakan metode prosedural sampling dengan jumlah responden penelitian sebanyak 150 karyawan. Teknik analisis yang digunakan adalah analisis jalur dengan Structural Equestion Modelling (SEM).
\end{abstract}

\footnotetext{
Abstrak

The phenomenon of job hopping or changing workplaces appeared in millennial generation. Turnover intention is the worst impact caused by inability of an organization to manage individual behavior, so that individuals feel they have a high turnover intention. The high level of turnover intention for millennial employees will have a negative impact on the company which can create instability and show that the company is ineffective, therefore a company must know the factors that can cause turnover intention. The purpose of this study was to examine the effect of Organizational Justice, Promotion Opportunities, Work Environment and Job Embeddedness on Turnover Intentions. This research was conducted at companies and MSMEs in service industry such as restaurants, hotels, hospitals and skincare. Sampling using procedural sampling method with 150 employees as respondents. The analysis technique used is path analysis with Structural Equestion Modeling (SEM).
} 


\section{PENDAHULUAN}

Fenomena job hopping atau berpindah-pindah tempat kerja muncul pada generasi yang lahir antara tahun 1980 hingga pertengahan tahun 2000-an atau yang lebih sering disebut dengan "generasi milenial". Hasil riset yang dirilis Pew Research Center menjelaskan bahwa hal yang mencolok dari generasi milenial adalah penggunaan teknologi dan kemandirian bekerja. Karena itu, salah satu ciri dari generasi milenial adalah mereka sangat percaya diri, berani mengemukakan pendapat, kreatif dan terbiasa untuk berpikir out of the box. ${ }^{1}$ Stigma itu juga didukung oleh hasil survei yang dilakukan oleh situs pencarian kerja Jobstreet.com pada tahun 2018. Hasil survei menunjukkan bahwa 65,8 persen generasi milenial memilih untuk meninggalkan pekerjaanya setelah bekerja selama satu tahun di perusahaan tersebut. ${ }^{2}$ Karena itu, muncullah fenomena turnover intention yang memiliki arti adanya niat karyawan untuk berhenti bekerja dari suatu organisasi kerja secara sukarela.

Turnover intention merupakan dampak terburuk yang disebabkan oleh ketidakmampuan suatu organisasi untuk mengelola perilaku individu, sehingga individu merasa memiliki intensi pindah kerja (turnover) yang tinggi (Ahsani, Sunarso dan Indriastuti, 2020) ${ }^{3}$. Tingginya tingkat turnover intention pada kayawan milenial akan menimbulkan dampak negatif bagi perusahaan yang dapat menciptakan ketidakstabilan dan menunjukkan bahwa perusahaan tersebut tidak efektif, oleh sebab itu suatu perusahaan harus mengetahui faktor-faktor yang dapat menyebabkan turnover intention (Alhamwan dan Mat, 20154). Faktor penyebab adanya turnover intentions salah satunya adalah keadilan organisasi. persepsi dari seorang karyawan mengenai keadilan organisasi sangatlah mempengaruhi sikap dan perilaku mereka dalam bekerja. Jika karyawan percaya bahwa meraka diperlakukan secara adil dan mendapatkan imbalan sesuai dengan apa yang mereka kontribusikan untuk perusahaan maka karyawan tidak akan meninggalkan perusahaannya. Crow, Lee, dan Joo (2012) menyatakan keadilan organisasi merupakan suatu perlakuan, maupun tindakan yang diterima oleh setiap karyawan sama tanpa memandang status jabatan atau kedudukan dan dapat dikatakan adil apabila karyawan mendapatkan hak-hak mereka sesuai dengan apa yang mereka kontribusikan kepada perusahaan. ${ }^{5}$

Selain Keadilan organisasi, turnover intentions juga dipengaruhi oleh kesempatan promosi. Seperti yang diungkapkan oleh Sari (2015) bahwa kesempatan memperoleh proosi jabatan di perusahaan akan mengurangi adanya keinginan karyawan untuk berpindah ataupun keluar dari pekerjaannya ${ }^{6}$. Cox dan Cheyne (2000) mengungkapkan bahwa setiap karyawan selalu menginginkan suasana kerja yang menyenangkan, nyaman, dan aman. ${ }^{7}$ Suasana kerja yang nyaman itu meliputi cahaya/penerangan yang jelas, suara yang tidak bising dan tenang, keamanan di dalam bekerja. Tersedianya fasilitas kerja yang lengkap, walaupun tidak baru merupakan salah satu penunjang proses kelancaran dalam bekerja. Lingkungan kerja yang aman dan semakin lengkap fasilitas yang

\footnotetext{
${ }^{1}$ https://www.pewresearch.org

2 https://www. jobstreet.co. id.

${ }^{3}$ Ahsani, R.F., Sunarso, dan Indriastuti, D. R. 2020. "Work Overload, Turnover Intentions, dan Work Family Conflicts pada Pegawai Perbankan Kota Surakarta". Research Fair Unisri. Vol.4, No.1, Pp 198.206.

${ }^{4}$ Alhamwan, M., dan Mat, N.B. 2015. "Antecedents of Turnover Intention Behavior among Nurses: A

Theoretical Review", Journal of Management and Sustainability, Vol.5, No.1, Pp. 84-89.

${ }^{5}$ Crow, M.S., Lee, C. dan Joo, J. 2012, "Organizational justice and organizational commitment among South Korean police officers: An investigation of job satisfaction as a mediator", Policing: An International Journal, Vol. 35 No. 2, Pp. 402-423.

${ }^{6}$ Sari, Evitamala. 2015. “Pengaruh Kepuasan Kerja, Komitmen dan Promosi Jabatan Terhadap Turnover Intention pada Karyawan PT. Orindo Alam Ayu Cabang Pekanbaru”. JOM FEKON. Vol. 2 No. 1, Pp. 1-15.

${ }^{7}$ Cox, S. J dan Cheyne, A. J. T. 2000. “Assessing Safety Culture in Ofshore Environment”. UK: Safety Science 34
} 
diterima karyawan untuk menunjang pekerjaannya maka semakin rendah niat karyawan untuk mengundurkan diri dari perusahaan.

Job embeddedness merupakan istilah untuk mewakili alasan-alasan yang membuat karyawan tetap bertahan di pekerjaan dan organisasi (Sun, 2011). ${ }^{8} \mathrm{Job}$ embeddedness dapat didefinisikan sebagai faktor-faktor yang mempengaruhi keputusan seseorang untuk bertahan atau meninggalkan pekerjaan dan organisasinya (Bergiel, Nguyen, dan Clenney., 2009) ${ }^{9}$. Berdasarkan temuan-temuan tersebut, maka penelitian ini akan menguji pengaruh keadilan organisasi kesempatan promosi, lingkungan kerja, dan job embeddedness terhadap turnover intentions pada karyawan sektor industri jasa di Indonesia dengan kriteria responden adalah generasi milenial.

\section{METODE PENELITIAN}

Penelitian ini merupakan penelitian kuantitatif jenis konfirmatoris dengan data cross-sectional yang dapat menjelaskan hubungan korelasional antar variabel melalui pengujian hipotesis, dengan desain penelitian survey. Metode pengumpulan data menggunakan self-administered survey.

Pengambilan sampel pada penelitian ini melalui non-probability sampling. Sampel penelitian ini adalah pegawai/karyawan perusahaan besar, kecil dan menengah yang bergerak di industri jasa di Indonesia. Sampel penelitian dipilih peneliti secara beragam dengan tujuan agar memperoleh data yang heterogen. Sampel unit dipilih karena mudah dijangkau oleh peneliti, jumlah dan karakteristik karyawan memenuhi kebutuhan penelitian yaitu minimal 5 kali jumlah indikator atau sebanyak 100 sampel. Penelitian ini akan menggunakan analisis regresi dengan SEM. Hubungan antar konstruk dalam hipotesis ditunjukkan oleh nilai regression weights.

\section{PEMBAHASAN}

Penyebaran kuesioner dilakukan dalam rentang waktu dari bulan Juni 2020 sampai dengan September 2020 dan mendapatkan 150 data responden untuk dapat dianalisis lebih lanjut.

Karakteristik responden untuk jenis kelamin didominasi oleh laki-laki dengan presentase sebesar 56,8\%, pada kategori umur paling banyak adalah rentang usia 30-40 tahun dengan presentase sebesar $40,50 \%$, untuk kategori tingkat pendidikan yang mendominasi adalah lulusan sarjana (S1) sebanyak $87 \%$ dan kategori masa kerja paling banyak adalah 1-2 tahun yaitu sebesar $56,4 \%$.

Hasil dari uji validitas menunjukkan semua item pertanyaan telah valid karena nilai factor loading di atas 0,5 dan seluruh variabel yaitu keadilan organisasi, kesempatan promosi, lingkungan kerja, job embededdness dan turnover intention dinyatakan reliabel dengan nilai CR (Conctruct Reliability) sama dengan atau di atas 0,7 (Hair, 2010). ${ }^{10}$

Berdasarkan keseluruhan pengukuran goodness-of-fit pada Tabel.1, dengan melakukan modification indeks, model penelitian ini telah sesuai kriteria. Selanjutnya analisis terhadap hubunganhubungan struktural model (pengujian hipotesis) dapat dilakukan. Dengan menggunakan analisis jalur dapat dihitung besarnya pengaruh langsung dari variabel-variabel bebas terhadap suatu variabel terikat. Hubungan antar konstruk dalam hipotesis ditunjukkan oleh regression weights.

\footnotetext{
${ }^{8}$ Sun, T. 2011. "The impact of psychological capital on job embeddedness and job performance among nurse : A structural equation approach". Journal of Advance Nursing, 61.

${ }^{9}$ Bergiel. E. B., Nguyen, V. Q., Clenney, B. F., Taylor, G.S. 2009. “Management Research News”, VI. 32, No.3, pp. 205-219.

${ }^{10}$ Hair, J. F. Jr. R. E, Anderson, R. L. T dan Black, W.C . 2010. “Multivariate Data Analysis”, 7th Edition. New York: Prentice Hall International, Inc.
} 
Tabel 1.

Hasil Goodness-of-Fit Model

\begin{tabular}{llll}
\hline Goodness of Fit indeks & Nilai yang Diharapkan & Hasil & Evaluasi \\
\hline$x^{2}-$ Chi Square & Diharapkan kecil & 12,842 & Baik \\
\hline Probabilitas & $\geqq 0,05$ & 0,074 & Baik \\
\hline CMIN/DF & $\leq 2$ & 1,519 & Baik \\
\hline GFI & $\geq 0,90$ & 0,956 & Baik \\
\hline AGFI & $\geq 0,90$ & 0,901 & Baik \\
\hline$T L I$ & $\geq 0,90$ & 0,932 & Baik \\
\hline CFI & $\geq 0,90$ & 0,903 & Baik \\
\hline RMSEA & $\leq 0,08$ & 0,056 & Baik \\
\hline
\end{tabular}

Sumber: UNISRI (2020)

Hasil uji hipotesis pada Tabel 2. terlihat bahwa keadilan organisasi berpengaruh terhadap turnover intentions, ini berarti $\mathbf{H 1}$ didukung. Penelitian ini membuktikan bahwa dengan adanya keadilan organisasi dapat mengurangi terjadinya turnover intentions. Didukungnya hipotesis ini menegaskan bahwa penelitian ini sesuai dengan penelitian yang dilakukan oleh Wiratama dan Suana (2015) yang menjelaskan bahwa bila seorang karyawan merasakan keadilan atas hasil yang diterimanya sebagai balas jasa atas kinerjanya akan menurunkan niat karyawan untuk mengundurkan diri dari perusahaan. ${ }^{11}$

Tabel 2.

Hasil Uji Hipotesis

\begin{tabular}{lccccc}
\hline \multicolumn{1}{c}{ Regression Weight } & Estimate & SE & $\boldsymbol{C R}$ & $\boldsymbol{P}$ & Ket \\
\hline $\begin{array}{l}\text { Keadilan Organisasi } \rightarrow \\
\text { Turnover Intentions }\end{array}$ &,- 654 &, 053 & 11,345 &, 021 & Sig \\
\hline $\begin{array}{l}\text { Kesempatan Promosi } \rightarrow \\
\text { Turnover Intentions }\end{array}$ &,- 903 &, 076 & 10,118 &, 002 & Sig \\
\hline $\begin{array}{l}\text { Lingkungan Kerja } \rightarrow \\
\text { Turnover Intentions }\end{array}$ &,- 326 &, 889 & 0,371 &, 068 & $\begin{array}{c}\text { Non } \\
\text { Sig }\end{array}$ \\
\hline $\begin{array}{l}\text { Job Embededdness } \rightarrow \\
\text { Turnover Intentions }\end{array}$ &,- 416 &, 053 & 15,011 &, 035 & Sig \\
\hline
\end{tabular}

Sumber: UNISRI, (2020)

Hasil uji hipotesis pada Tabel 2. menunjukkan bahwa kesempatan promosi berpengaruh terhadap turnover intentions karyawan. Dengan hasil tersebut, dapat disimpulkan bahwa H2 didukung. Adapun pengaruh yang ditimbulkan bersifat negatif. Artinya, semakin tinggi kesempatan promosi maka turnover intentions akan semakin berkurang. Hasil penelitian ini mendukung penelitian sebelumnya dimana karyawan yang memiliki kemajuan karir dalam tempatnya bekerja akan mengurangi niatnya untuk meninggalkan pekerjaannya begitupun sebaliknya, karyawan yang tidak memiliki kemajuan karir akan meningkatkan keinginannya untuk keluar dari pekerjaannya untuk

\footnotetext{
${ }^{11}$ Wiratama, D.W, dan Suana I. W. 2015." Pengaruh Keadilan Organisasi terhadap Kepuasan Kerja dan Turnover Intention pada Karyawan The Jayakarta Bali". E-Journal Manajemen Unud, Vol.4, No.11. Pp 36753702
} 
mencari peluang lain di tempat lain. Dalam penelitain ini ditemukan bahwa para milenial cenderung memiliki dorongan dan semangat yang tinggi dalam berkarir, sehingga dengan adanya kesempatan promosi jabatan akan menekan niatan untuk meninggalkan pekerjaannya.

Lingkungan Kerja dapat mempengaruhi turnover intention yang tertuang dalam Hipotesis 3 (H3) Tidak Didukung. Pada Tabel 2. diketahui bahwa lingkungan kerja tidak berpengaruh terhadap turnover intention karyawan dengan nilai $S E 0,089$ di atas nilai $C R 0,371$ pada probabilitas 0,068 > 0,05 . Hasil ini tidak sesuai dengan penelitain terdahulu yang dilakukan oleh Cox dan Cheyne (2000) yang menyatakan bahwa seseorang akan bertahan bila merasakan aman dan nyaman pada lingkungan kerjanya. Berdasarkan hasil observasi penelitian, para milenial berpendapat bahwa lingkungan kerja tidak signifikan dalam menekan turnover intentions. Hal ini disebabkan karena kebanyakan milineal mampu dengan cepat menyesuaikan diri pada lingkungan kerja. Sehingga lingkungan kerja dengan desain yang baik juga tidak mampu menekan keinginan mereka untuk berpindah maupun meninggalkan pekerjaannya.

Hasil uji hipotesis pada Tabel 2. menunjukkan bahwa job embededdness berpengaruh terhadap turnover intentions karyawan atau $\mathbf{H 4}$ didukung. Pengaruh yang ditimbulkan bersifat negatif., artinya semakin tinggi job embededdness maka turnover intentions akan semakin berkurang. Hasil penelitian ini mendukung penelitian sebelumnya yang pernah diteliti oleh dilakukan Tanova dan Holtomb (2008), menunjukkan bahwa keputusan karyawan untuk melakukan turnover tidak hanya dipengaruhi oleh sikap kerja individu dan peluang yang ada tetapi juga job embeddedness. ${ }^{12} \mathrm{Job}$ embeddedness bagi milineal ternyata memiliki manfaat yang baik dalam mengurangi turnover intentions. Keterikatan karyawan dalam suatu organisasi melalui jaringan sosial, yaitu kepercayaan, kohesi dan semua faktor yang melibatkan karyawan dalam pekerjaan mereka dapat membentuk nilainilai pekerjaan yang mirip dengan nilai individu. Keterikatan inilah yang kemudian menyebabkan karyawan enggan untuk meninggalkan atau berpindah pekerjaan.

\section{KESIMPULAN}

Penelitian ini membuktikan bahwa dengan adanya keadilan organisasi dapat mengurangi terjadinya turnover intentions. Hasil Penelitian ini juga menunjukkan bahwa dengan semakin tinggi kesempatan promosi yang diberikan oleh perusahaan maka dapat mengurangi keinginan para karyawan milenial untuk keluar atau bepindah kerja. Sedangkan variabel lingkungan kerja ternyata tidak memiliki pengaruh pada tingkat turnover intentions karyawan. Dan terakhir hasil penelitian menunjukan bahwa semakin tinggi job embededdness maka turnover intentions akan semakin berkurang.

Pada riset ini, responden melakukan self-report, sehingga sangat berpotensi menimbulkan common method bias yang disebabkan oleh bias karena sumber penilai yang sama (common rater effect bias). Eksplorasi informasi responden sangat terbatas karena tidak mampu mencari keterangan lebih lanjut terhadap responden karena penelitian hanya menggukan kuesioner. Untuk menambahkan kekayaan informasi dan tambahan pengetahuan pada saat penyusunan hasil riset, penelitian selanjutnya dapat menggunakan metode triangulasi, misalnya dengan menggunakan survei dilengkapi dengan wawancara. Penelitian kedepan dapat memperkuat hasil uji hipotesis untuk melihat hubungan kausalitas turnover intentions dengan variabel konsekuensinya dengan menggunakan metode longitudinal.

\footnotetext{
12 Tanova, C., dan Holtom, B. C. 2008. "Using job embeddedness factors to explain voluntary turnover in four European countries", Vol. 19, No. 9, Pp. 1553-1568.
} 


\section{DAFTAR PUSTAKA}

Ahsani, R.F., Sunarso, dan Indriastuti, D. R. 2020. "Work Overload, Turn Over Intention, dan Work Family Conflicts pada Pegawai Perbankan Kota Surakarta". Research Fair Unisri. Vol.4, No.1, Pp 198.206.

Alhamwan, M., dan Mat, N.B. 2015. "Antecedents of Turnover Intention Behavior among Nurses: A Theoretical Review", Journal of Management and Sustainability, Vol.5, No.1, Pp. 84-89.

Bergiel. E. B., Nguyen, V. Q., Clenney, B. F., Taylor, G.S. 2009. "Management Research News", Vol. 32, No.3, pp. 205-219.

Cox, S. J dan Cheyne, A. J. T. (2000). Assessing Safety Culture in Ofshore Environment. UK: Safety Science 34

Crow, M.S., Lee, C. dan Joo, J. 2012, "Organizational justice and organizational commitment among South Korean police officers: An investigation of job satisfaction as a mediator", Policing: An International Journal, Vol. 35 No. 2, Pp. 402-423.

Hair, J. F. Jr. R. E, Anderson, R. L. T dan Black, W.C . 2010. "Multivariate Data Analysis", 7th Edition. New York: Prentice Hall International, Inc.

https://www. jobstreet.co. id. Diakses pada tanggal 10 Januari 2020 pukul 20.00 WIB

https://www.pewresearch.org. Diakses pada tanggal 10 Januari 2020 pukul 20.10 WIB

Sari, Evitamala. 2015. "Pengaruh Kepuasan Kerja, Komitmen dan Promosi Jabatan Terhadap Turnover Intention pada Karyawan PT. Orindo Alam Ayu Cabang Pekanbaru". JOM FEKON. Vol. 2 No. 1, Pp. 1-15.

Sun, T. 2011. "The impact of psychological capital on job embeddedness and job performance among nurse : A structural equation approach". Journal of Advance Nursing, 61.

Tanova, C., dan Holtom, B. C. 2008. "Using job embeddedness factors to explain voluntary turnover in four European countries", Vol. 19, No. 9, Pp. 1553-1568.

Wiratama, D.W, dan Suana I. W. 2015." Pengaruh Keadilan Organisasi terhadap Kepuasan Kerja dan Turnover Intention pada Karyawan The Jayakarta Bali". E-Journal Manajemen Unud, Vol.4, No.11. Pp 3675-3702. 